\title{
Analisis Pengolahan Sampah Berbasis Zero Waste sebagai Salah Satu Upaya Universitas Semarang (USM) mewujudkan Eco-Campus Sudanti ${ }^{1}$, Hanjani Antania Andary ${ }^{2}$,Sri Yusmiati ${ }^{3}$ \\ 1) Jurusan Teknik Sipil Universitas Semarang \\ 2) Jurusan Teknik Sipil Universitas Semarang \\ 3) Jurusan Teknik Sipil Universitas Semarang
}

\begin{abstract}
For Semarang Universitymore known and known by many circles, then Semarang University requires a branding. With the Eco-campus program, it will open the opportunity to create a prototype branding so that Semarang University can be superior and well known to the public both inside and outside the country. The eco-campus program is motivated by the hope that the campus environment becomes a comfortable, clean, shady (green), beautiful and healthy place for students to gain knowledge. The purpose of this research is to know Waste Management Pattern at Semarang University, Waste Processing Process with Zero Waste Concept that will be applied to manage Organic and Inorganic waste generated from activity at Semarang University and apply One of Eco-Campus Program indicators to print educator staff, college staff and students with an eco-friendly science and technology in accordance with Semarang University vision and mission. The research was conducted in Semarang University environment, both in faculty environment and in Temporary Garbage Disposal Site. Existing Condition of Garbage Disposal Site. While at Semarang University there is no sorting process and no roof, so if rain, rain water into container and garbage become wet, can cause odor. Generation of waste generated Semarang University.
\end{abstract}

Keywords: concept of waste processing, branding, eco campus

\begin{abstract}
Abstrak
Agar USM lebih di kenal dan diketahui oleh banyak kalangan, maka USM membutuhkan sebuah branding. Dengan adanya program Eco-campus ini, akan membuka kesempatan untuk membuat branding prototipe agar USM mampu lebih unggul dan dikenal nasyarakat baik di dalam maupun di luar negeri. Program eco-campus dilatarbelakangi harapan agar lingkungan kampus menjadi tempat yang nyaman, bersih, teduh (hijau), indah dan sehatbagi mahasiswa untuk menimba ilmu pengetahuan. Penelitian ini bertujuan untuk mengetahui Pola Pengelolaan Sampah di Universitas Semarang (USM), proses Pengolahan Sampah dengan Konsep Zero Waste yang akan diterapkan untuk mengelola sampah Organik dan Anorganik yang dihasilkan dari kegiatan di Universitas Semarang (USM) serta mengaplikasikan Salah satu indikator Program Eco-campus untuk mencetak staf pendidik, staf perguruan tinggi dan mahasiswa-mahasiswa yang mempunyai IPTEK berwawasan lingkungan sesuai dengan visi dan misi USM. Penelitian dilakukan di Lingkungan Universitas Semarang, baik di lingkungan fakultas maupun di Tempat Pembuangan Sampah Sementara (TPS). Kondisi eksisting Tempat Pembuangan Sampah (TPS) Sementara di Universitas Semarang (USM) belum ada proses pemilahan dan tidak ada atapnya, sehingga apabila hujan, air hujan masuk ke dalam container dan sampah-sampah menjadi basah, bisa menimbulkan bau tak sedap.Timbulan sampah yang dihasilkan kampus Universitas Semarang (USM)dalam satu minggu adalah $2.310 \mathrm{~kg}$, sehingga didapatkan jumlah timbulan sampah dalam satu hari adalah $330 \mathrm{~kg} / \mathrm{hari}$. Komposisi timbulan sampah yang dihasilkan kampus Universitas Semarang terdiri dari sampah organik $(65,24 \%)$, sampah kertas $(10,56 \%)$, sampah plastik $(23,77 \%)$ dan sampah lainnya sebanyak $(0,43 \%)$.
\end{abstract}

Kata kunci: konsep pengolahan sampah, branding, eco campus

\section{PENDAHULUAN}

Menurut Badan Lingkungan Hidup (BLH) Surabaya (2011),Eco-campus didefinisikan sebagai kampus yang peduli dan berbudaya lingkungan dan telah melakukan pengelolaan lingkungan secara sistematis dan berkesinambungan. Eco-campus merupakan refleksi dari keterlibatan 
seluruh civitas akademika yang berada dalam lingkungan kampus agar selalu memperhatikan aspek kesehatan dan lingkungan di sekitarnya. Beberapa indikator terciptanya eco-campus antara lain adanya kebijakan manajemen kampus yang berorientasi pada pengelolaan lingkungan, adanya upaya penghematan air, kertas, dan listrik, adanya penghijauan untuk mencapai proporsi ideal Ruang Terbuka Hijau (RTH), tersedianya bangunan/gedung ramah lingkungan, terpeliharanya kebersihan dan kenyamanan lingkungan, terciptanya kampus tanpa rokok dan bebas polusi, terselenggaranya pendidikan lingkungan bagi mahasiswa, serta adanya kepedulian dan keterlibatan seluruh elemen civitas akademika dalam budaya peduli lingkungan.

Untuk mencapai indikator-indikator yang sangat komprehensif tersebut diperlukan tindakan nyata yang berkesinambungan dan bukan sekedar seremonial atau event belaka.Untuk itu, perubahan pola pikir seluruh civitas akademika dalam menyikapi dan memperlakukan lingkungan secara benar merupakan langkah awal yang perlu terus diupayakan.USM memulai langkah dengan membuat Konsep Manajemen Pengelolaan Sampah yang mengacu pada Konsep Zero Waste Solution. Pengelolaan sampah akan dilaksanakan dengan pembuatan Program Pengolahan Sampah dengan system Komposting dan 3R (reduce, reuse, recycle) yang akan diterapkan untuk mengelola sampah organik dan anorganik yang dihasilkan dari kegiatan belajar mengajar di kampus USM dan masyarakat sekitar kampus.

Kontribusi dari hasil penelitian ini terhadap pembangunan pengembangan IPTEKS, pengembangan institusi dan potensi peran serta civitas akademika serta masyarakat adalah penerapan teknologi yang dibutuhkan agar sampah di Kampus USM terkelola dengan cepat dan terpadu. Penelitian ini merupakan langkah awal Universitas Semarang (USM) dalam Proyek Kepedulian Lingkungan, yang diharapkan akan mendorong penelitian-penelitian lain dalam perwujudan Eco-Campus. Penelitian ini diharapkan menjadi motivasi bagi dosen untuk mengembangkan penelitian yang berkaitan dengan Pengelolaan Sampah yang diintegrasikan dengan indikator-indikator pengelolaan lingkungan yang lain untuk mewujudkan Eco-campus.

\section{METODE PENELITIAN}

Penelitian ini merupakan penelitian eksploratif menggunakan metode gabungan yakni kuantitatif dan kualitatif agar dapat diketahui jumlah dan komposisi timbulan sampah serta dinamika realitas sosial yang ada sehingga kendala dan strategi pengelolaan dapat dirumuskan. Penelitian ini di laksanakan dalam kurun waktu empat bulan. Berikut ini adalah Diagram Rancangan Penelitian Konsep Pengolahan Sampah Zero Waste sebagai upaya Universitas Semarang (USM) dalam rangka mewujudkan Eco-Campus : 


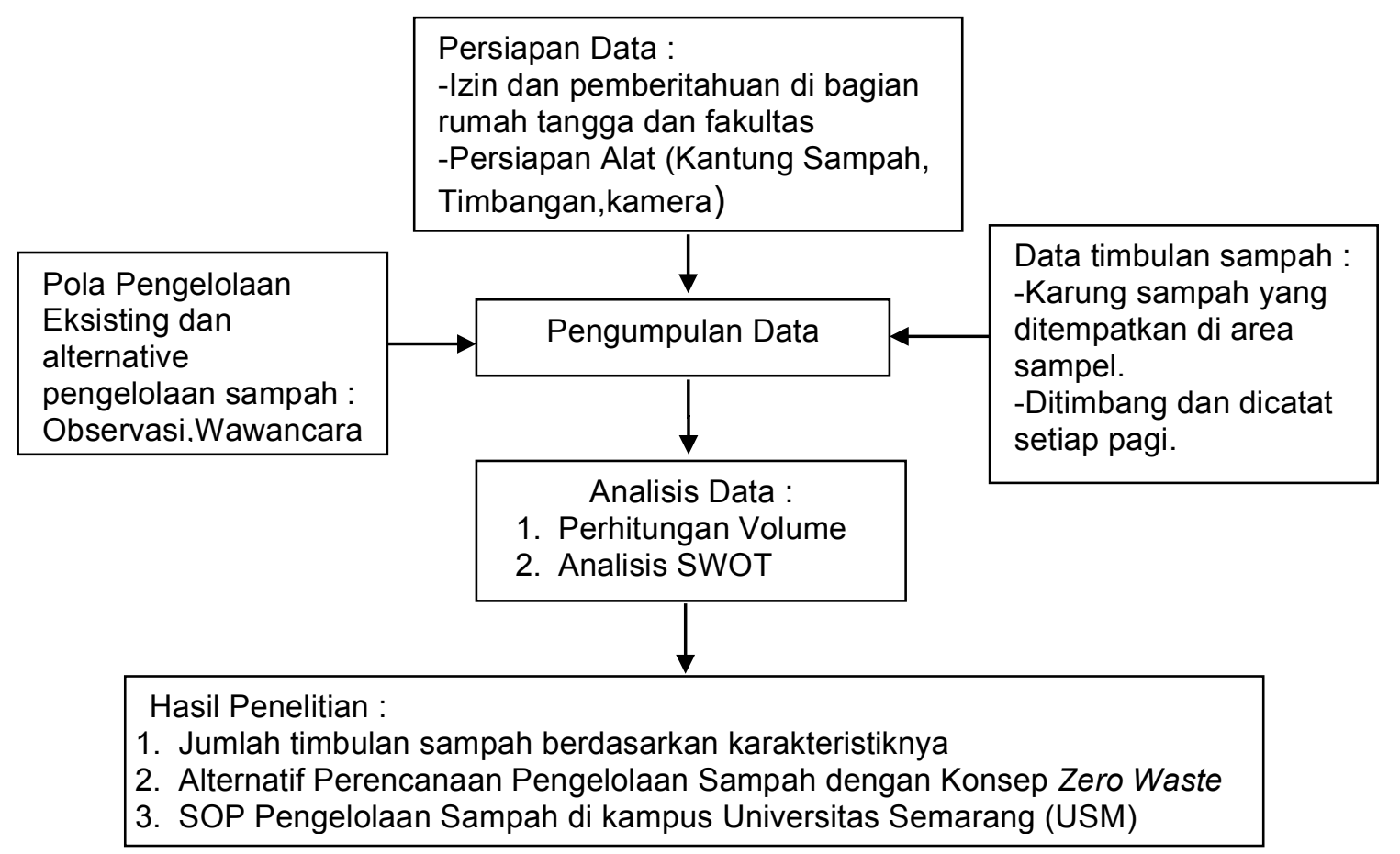

Sumber : Hasil Analisis Peneliti, 2017

\section{Gambar 1. Diagram Alur Rancangan Penelitian}

Analisis pada penelitian ini dibagi menjadi dua, yaitu bagian teknis yang akan membahas volume sampah berdasarkan karakteristiknya dan bagian non-teknis yang membahas permasalahan serta faktor prioritas dalam pengelolaan sampah di Kampus Universitas Semarang serta analisis SWOT.

\section{HASIL DAN PEMBAHASAN}

Kondisi eksisting tempat sampah, kondisi eksisting Tempat Pembuangan Sementara (TPS) dan jumlah tempat sampah di lingkungan Universitas Semarang (USM) ditunjukkan pada gambar 2.
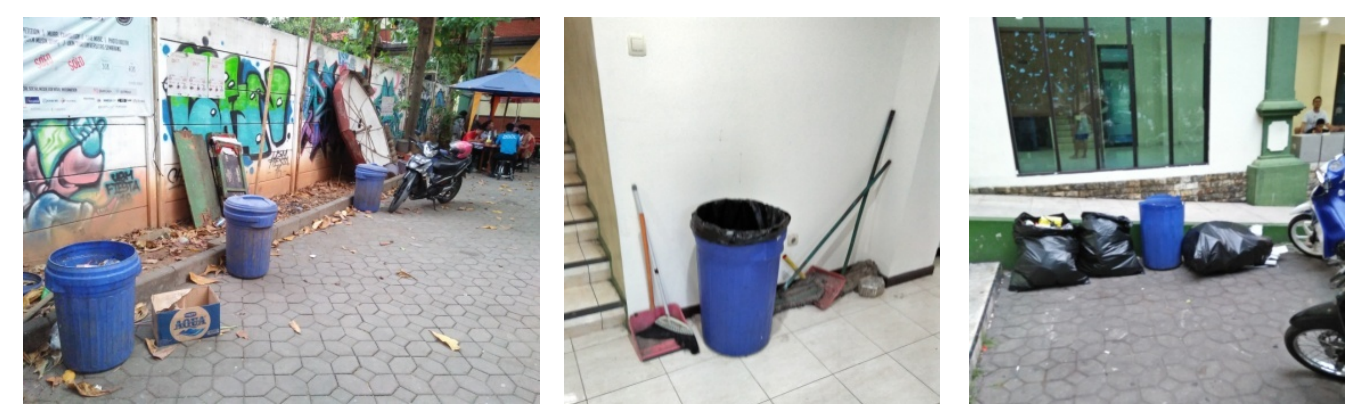

Sumber : Dokumentasi Peneliti, 2017

Gambar 2. Kondisi Eksisting Tempat Sampah di Universitas Semarang (USM) 
Dari hasil pengamatan lapangan disertai dengan dokumentasi tiap tempat sampah yang ada di setiap ruangan baik di dalam gedung maupun di luar gedung di lingkungan Universitas Semarang (USM) terlihat sangat rapi dan bersih, Namun memang ada beberapa tempat sampah yang sudah rusak bahkan tidak ada tutupnya, sehingga pada saat hujan, tempat sampah tersebut akan kemasukan air hujan. Selain itu, ada juga yang tempat sampahnya tidak cukup, sehingga sampahsampah dimasukan langsung ke dalam sampah pastik hitam. Resiko yang akan terjadi adalah adanya ceceran sampah, sehingga perlu ditambah jumlah tong sampah di titik-titik tertentu seperti kantin atau Kopma, atau di daerah tempat parkir dan area gedung $L$ (Gedung workshop). Kondisi eksisting TPS ditunjukkan gambar 3.
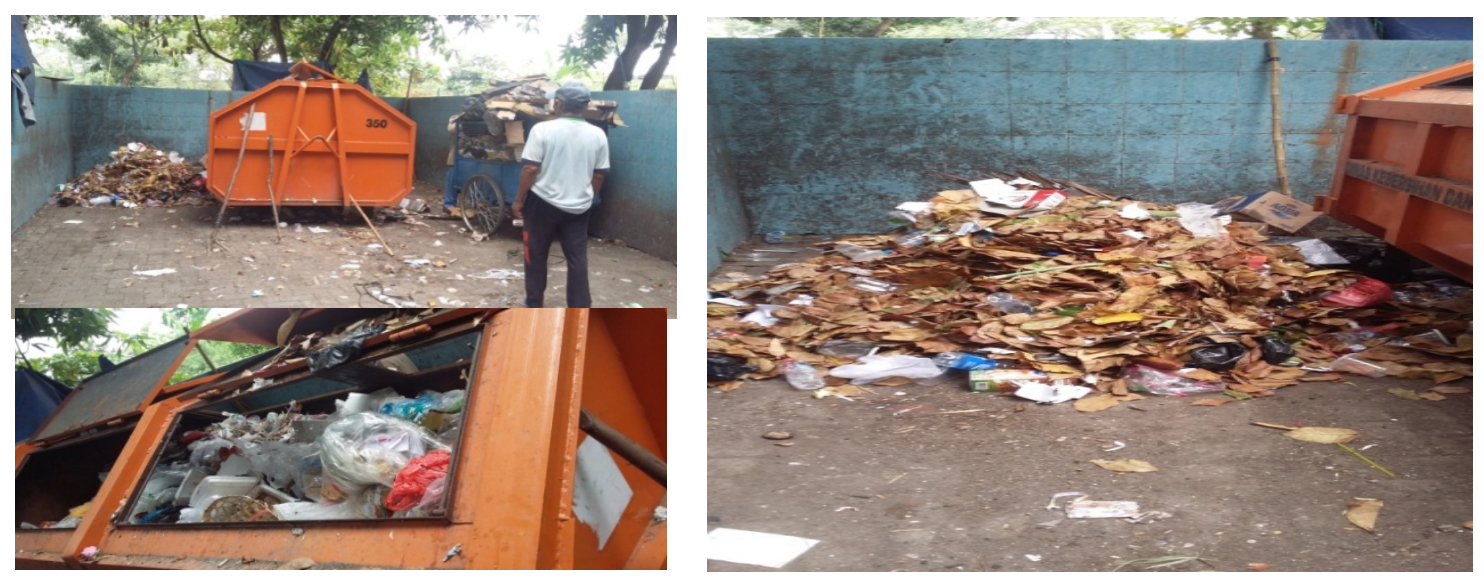

Sumber : Dokumentasi Peneliti, 2017

Gambar 3. Kondisi Eksisting Tempat Pembuangan Sementara (TPS) di Universitas Semarang (USM)

Kondisi eksisting Tempat Pembuangan Sampah (TPS) Sementara di Universitas Semarang (USM) belum ada proses pemilahan dan tidak ada atapnya, sehingga apabila hujan, air hujan masuk ke dalam container dan sampah-sampah menjadi basah, bisa menimbulkan bau tak sedap.

Tabel 1. Data Jumlah Tempat Sampah di Universitas Semarang (USM)

\begin{tabular}{|c|l|l|c|}
\hline No & \multicolumn{1}{|c|}{ Jenis Tempat Sampah } & \multicolumn{1}{|c|}{ Ukuran } & Jumlah (buah) \\
\hline 1 & Ukuran Besar 120 liter & $\begin{array}{l}\text { Diameter } 50 \mathrm{~cm} \\
\text { Tinggi } 60 \mathrm{~cm}\end{array}$ & 58 \\
\hline 2 & Ukuran Sedang 23 liter & $\begin{array}{l}\text { Diameter } 23 \mathrm{~cm} \\
\text { Tinggi } 55 \mathrm{~cm}\end{array}$ & 79 \\
\hline 3 & Ukuran Kecil 6 liter & $\begin{array}{l}\text { Panjang } 15 \mathrm{~cm} \\
\text { Lebar } 15 \mathrm{~cm} \\
\text { Tinggi } 25 \mathrm{~cm}\end{array}$ & $\mathbf{1 4 6}$ \\
\hline
\end{tabular}

Sumber : Hasil Pengamatan, 2017 


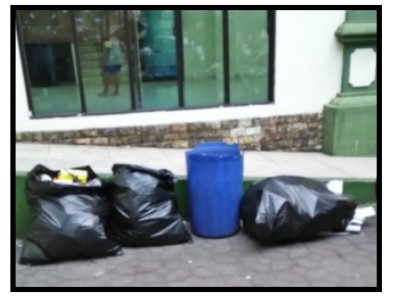

Sampah dari setiap gedung

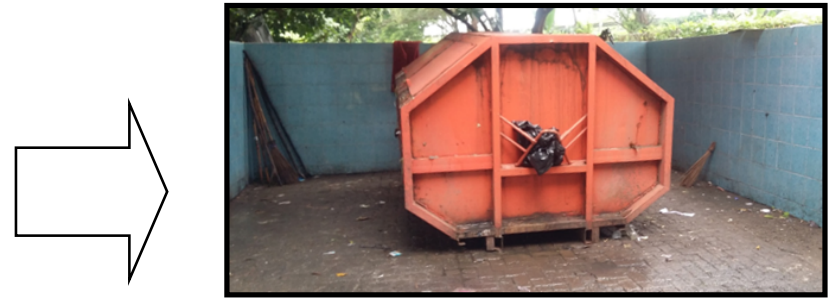

Sampah dari setiap gedung dimasukan ke dalam container di TPS Universitas Semarang
Sampah Kertas, Karton, Dus dijual
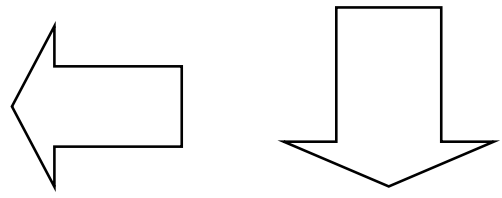

Sisa Sampah dibuang ke Tempat

Pembuangan Akhir

Sampah (TPA)

Sumber : Hasil Pengamatan, 2017

Gambar 4. Alur Pengelolaan Sampah Pada Kondisi Eksisting di Universitas Semarang (USM)

Hasil Penelitian dalam penelitian "Analisis Pengolahan Sampah berbasis Zero Waste sebagai Salah Satu Upaya Universitas Semarang (USM) mewujudkan Eco-Campus" ini adalah :

\section{Jumlah Timbulan Sampah Berdasarkan Karakteristiknya}
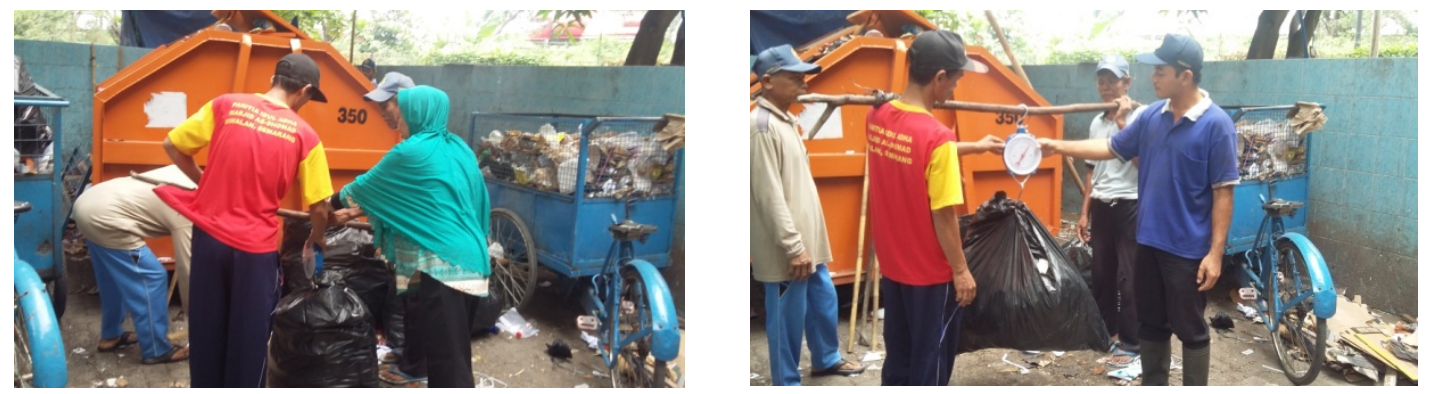

Sumber : Hasil Pengamatan, 2017

\section{Gambar 5. Dokumentasi penimbangan sampah Universitas Semarang (USM)}

Timbulan sampah yang dihasilkan kampus Universitas Semarang (USM)dalam satu minggu adalah $2.310 \mathrm{~kg}$, sehingga didapatkan jumlah timbulan sampah dalam satu hari adalah 330 $\mathrm{kg} /$ hari. Komposisi timbulan sampah yang dihasilkan kampus Universitas Semarang terdiri dari sampah organik $(65,24 \%)$, sampah kertas $(10,56 \%)$, sampah plastik $(23,77 \%)$ dan sampah lainnya sebanyak $(0,43 \%)$ 
Sistem pengelolaan sampah kampus Universitas Semarang (USM) terdiri dari 5 aspek perencanaan yaitu aspek teknik operasional, kelembagaan, peraturan dan regulasi, pembiayaan dan peran serta mahasiswa. Pengelolaan sampah Universitas Semarag (USM) dari mulai kegiatan pewadahan sampah sampai pengumpulan sampah atau pembakaran sampah dilakukan secara terpadu oleh Universitas. Aspek teknik operasionalnya menjadi tanggung jawab pengelola pusat, yaitu Bagian Rumah Tangga Universitas, Kemudian untuk Aspek pembiayaanya dikelola oleh Bagian Keuangan Universitas, sedangkan untuk aspek kelembagaan serta aspek regulasi ditangani oleh bagian akademik Universitas. Yang menjadi kendala pada pengelolaan persampahan di Universitas Semarang (USM) ini adalah kurangnya peran serta mahasiswa dalam pengelolaan sampah di Kampus Universitas Semarang (USM).

Selain itu, hal utama yang harus diperbaiki dalam proses pewadahan sampah kampus Universitas Semarang (USM) adalah penyediaan wadah sampah yang terpilah sesuai dengan karakter timbulan sampah yang dihasilkan. Penyediaan wadah sampah yang terpilah sekaligus akan menggantikan wadah sampah yang sudah rusak.

\section{Konsep Zero Wastemenggunakan Analisis SWOT}

Analisis SWOT dimulai dengan mengkaji faktor internal dan kondisi lingkungan eksternal Universitas Semarang (USM). Faktor-faktor internal (kekuatan dan kelemahan) dan eksternal (peluang dan ancaman) dalam pengelolaan sampah berbasis Zero Waste di Universitas Semarang (USM) tersebut dapat dilihat dalam tabel dibawah ini :

Tabel 2. Faktor-Faktor Internal dan Eksternal dalam Analisis SWOT Pengelolaan Sampah berbasis Zero Waste di Universitas Semarang (USM)

\begin{tabular}{|c|c|c|}
\hline & Kekuatan (Strengths) & Kelemahan (Weaknesses) \\
\hline $\begin{array}{c}\text { I } \\
\mathbf{N} \\
\mathbf{T} \\
\mathrm{E} \\
\mathrm{R} \\
\mathbf{N} \\
\mathrm{A} \\
\mathrm{L}\end{array}$ & $\begin{array}{l}\text { 1. Kesesuaian visi dan misi dengan } \\
\text { kondisi. } \\
\text { 2. Peran Universitas dalam membina } \\
\text { mahasiswa berkaitan tentang } \\
\text { pengelolaan sampah } \\
\text { 3. Dukungan stakeholder dalam } \\
\text { pengelolaan sampah terpadu } \\
\text { 4. Ada SDM Pengelola Sampah } \\
\text { Universitas. } \\
\text { 5. Pengelolaan keuangan satu pintu di } \\
\text { bagian keuangan Universitas. }\end{array}$ & $\begin{array}{l}\text { 1. Sarana dan Prasarana belum } \\
\text { sepenuhnya menunjang. } \\
\text { 2. Belum adanya Pemilahan Sampah } \\
\text { di Sumber. } \\
\text { 3. Belum ada Protap (prosedur tetap) } \\
\text { pengelolaan sampah Universitas } \\
\text { Semarang. } \\
\text { 4. Perencanaan pengelolaan sampah } \\
\text { kurang detil/spesifik. } \\
\text { 5. Kurang terpenuhinya standar } \\
\text { pengelolaan sampah. }\end{array}$ \\
\hline & Peluang (Opportunities) & Ancaman (Threats) \\
\hline $\begin{array}{l}\mathrm{E} \\
\mathrm{K} \\
\mathrm{S} \\
\mathrm{T}\end{array}$ & $\begin{array}{l}\text { 1. Ada dukungan dari Gubernur dalam } \\
\text { penerapan pengelolaan sampah } \\
\text { terpadu. } \\
\text { 2. Kondisi lingkungan politik yang } \\
\text { mendukung, terutama dalam } \\
\text { alokasi anggaran oleh legislatif dan } \\
\text { usulan Perda baru inisiatif legislatif. }\end{array}$ & $\begin{array}{l}\text { 1. Kesadaran warga kampus untuk } \\
\text { memilah dan mengelola sampah } \\
\text { masih minim. } \\
\text { 2. Belum ada peran serta dari } \\
\text { mahasiswa sebagai sumber sampah } \\
\text { terbesar. } \\
\text { 3. Ada pihak tertentu yang mencari }\end{array}$ \\
\hline
\end{tabular}




\begin{tabular}{|c|l|l|}
\hline $\mathbf{R}$ & 3. Disediakan dana untuk improve & keuntungan dari sampah Universitas \\
$\mathbf{N}$ & pengelolaan persampahan sebagai & Semarang. \\
$\mathbf{A}$ & branding Universitas. & \\
$\mathbf{L}$ & 4. Adanya tempat & \\
& pelatihan/pendidikan lewat pusat & \\
& pelatihan USM untuk meningkatkan & \\
& keahlian pengelolaan sampah. & \\
\hline
\end{tabular}

Sumber : Hasil Pengamatan, 2017

Dari hasil penelitian berupa Matrik SWOT dapat dibentuk sebuah Model Perencanaan Pengelolaan Sampah berbasis Zero Waste di Universitas Semarang (USM) sebagai berikut :

Tabel 3. Model Perencanaan Pengelolaan Sampah berbasis Zero Waste sebagai Salah Satu Upaya Universitas Semarang dalam mewujudkan Ecocampus

\begin{tabular}{|c|c|c|}
\hline No & Kondisi Eksisting & $\begin{array}{c}\text { Perencanaan Pengelolaan Sampah } \\
\text { berbasis Zero Waste di Universitas } \\
\text { Semarang }\end{array}$ \\
\hline 1. & - Tempat sampah dicampur jenisnya & $\begin{array}{l}\text { sampah organik dan sisa makanan } \\
\text { kantin, plastik, residu) }\end{array}$ \\
\hline 2. & $\begin{array}{l}\text { - Kontainer di TPS masih } \\
\text { mencampurkan antara sampah } \\
\text { organik dan anorganik, belum ada } \\
\text { pemisahan jenis sampah. } \\
\text { - Belum ada pengolahan sampah di } \\
\text { TPS. } \\
\text { - TPS tidak ada atapnya, kalau hujan, } \\
\text { air hujan masuk sehingga } \\
\text { menimbulkan bau yang tidak sedap. }\end{array}$ & $\begin{array}{l}\text { Perencanm TPS 3R bertingkat } \\
\text { di USM } \\
\text { - Me } \text { unuat I } \text { u uerlyaı senat sesuai } \\
\text { dengan sampah yang akan di Recycle, } \\
\text { Reuse dan Recovery (3R) } \\
\text { - Membi TPS } \\
\text { Terpadu Kampus Universitas Semarang } \\
\text { (USM) }\end{array}$ \\
\hline
\end{tabular}




\section{SOP Pengelolaan Sampah di Kampus Universitas Semarang}

Dari hasil penelitian melalui analisis dengan matrik SWOT ini, dapat dibuat suatu prosedur atau Standar Operasional Prosedur (SOP) pengelolaan sampah berbasis Zero Waste guna mewujudkan Eco-campus di Universitas Semarang (USM). SOP terlampir.

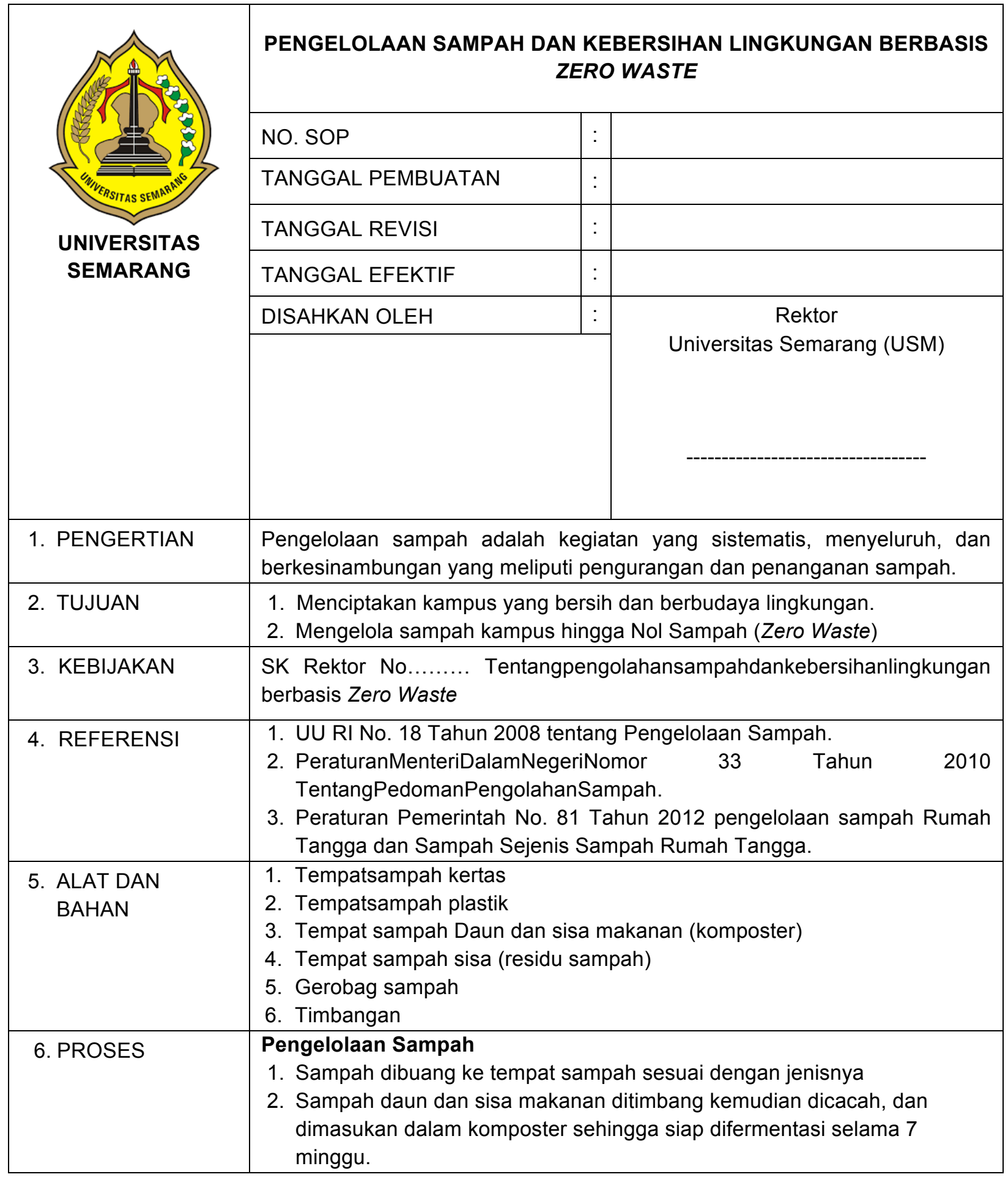




\begin{tabular}{|c|c|}
\hline & $\begin{array}{l}\text { 3. Sampah kertas, plastik, kardus dan kaleng masing-masing ditimbang } \\
\text { kemudian dijual dan dicatat (berapa jumlah timbulan dan berapa rupiah } \\
\text { yang dihasilkan). Uangnya dimasukan ke dalam Kas TPST. } \\
\text { 4. Sampah residu dikirim ke TPA dengan pick up sampah USM. }\end{array}$ \\
\hline 7. UNIT TERKAIT & $\begin{array}{l}\text { 1. Bagian Rumah Tangga } \\
\text { 2. Bagiankebersihan }\end{array}$ \\
\hline $\begin{array}{l}\text { 8. DOKUMEN } \\
\text { TERKAIT }\end{array}$ & $\begin{array}{l}\text { 1. JadwalPetugasKebersihan } \\
\text { 2. Catatan Monitoring Tabel Jumlah timbulan sampah setiap hari } \\
\text { (checklist) } \\
\text { 3. Catatan Monitoring danEvaluasiPetugas }\end{array}$ \\
\hline
\end{tabular}

Sumber : Dokumentasi Peneliti, 2017

\section{KESIMPULAN}

Kesimpulan dari penelitian "Analisis Pengelolaan Persampahan berbasis Zero Waste sebagai salah satu upaya Universitas Semarang dalam mewujudkan Eco-campus" menghasilkan 3 hasil yaitu :

1. Timbulan sampah yang dihasilkan kampus Universitas Semarang (USM)dalam satu minggu adalah $2.310 \mathrm{~kg}$, sehingga didapatkan jumlah timbulan sampah dalam satu hari adalah 330 $\mathrm{kg} /$ hari. Komposisi timbulan sampah yang dihasilkan kampus Universitas Semarang terdiri dari sampah organik $(65,24 \%)$, sampah kertas $(10,56 \%)$, sampah plastik $(23,77 \%)$ dan sampah lainnya sebanyak $(0,43 \%)$.

2. Model Perencanaan Pengelolaan Sampah berbasis Zero Waste di Universitas Semarang (USM)

3. Standar Operasional Prosedur (SOP) pengelolaan sampah berbasis Zero Waste guna mewujudkan Eco-campus di Universitas Semarang (USM).

\section{DAFTAR PUSTAKA}

BLH Surabaya."Program Surabaya Eco-Campus (SEC) di Wilayah Surabaya". (http://lh.surabaya.go.id/ecocampus/index.html diakses tanggal 2 Maret 2017).

Clarke, A. and Kouri, R. 2009, Choosing An Appropriate University or College Environmental Management System, Journal of Cleaner Production, Vol. 17, pp. 971-84.

Ghani, S.R.W., 2016, Analisa Potensi Sampah Kampus berbasis Permodelan Maket di Gedung B Unhasy.

Hadisuwito, S., 2008, Membuat Pupuk Kompos Cair, AgroMedia Pustaka: Jakarta.

Fadhilah, A., Sugianto, H., Hadi, K., Firmandhani, S.W., Murtini, T.W., dan Pandelaki, E.E, 2011, Kajian Pengelolaan Sampah Kampus Jurusan Arsitektur Fakultas Teknik Universitas Diponegoro, ISSN: 0853-2877. Vol.11. No.2.

Khair, H., 2011., Persepsi Masyarakat Kampus Terhadap Kampus Yang Berwawasan Lingkungan (EcoCampus) Di Universitas Muhammadiyah Sumatera Utara, Jurnal Agrium, Oktober 2011. Vol. 17 No.1 hlmn 66-70.

Martono, H.D., dan Bebassari, S., 2011, Bank Sampah, Bahan Presentasi disampaikan pada Rapat Kerja Teknis Bank Sampah di Jogjakarta Plaza Hotel, Yogyakarta.

Mirwan, M., 2008, Optimasi Pengelolaan Sampah di Kampus UPN "Veteran" Jawa Timur. Jurnal Rekayasa Perencanaan. Vol. 4. No. 2.

Murbandono,, 2008, Membuat Kompos, Penebar Swadaya: Jakarta.

Putra, H.P., dan Yuriandala, Y., 2010, Studi Pemanfaatan Sampah Plastik Menjadi Produk dan Jasa Kreatif, Jurnal Sains dan Teknologi Lingkungan. Vol.2, No. 1.hal. 21-31.

Sugiyono, 2011. "Metode Penelitian Kuantitatif Kualitatif dan R\&D". Penerbit Alfabeta, Bandung. 
S, T. L., 2016, Pengolahan Sampah di Perguruan Tinggi dan Kontribusinya Terhadap Penurunan Emisi Gas Rumah Kaca, Prosiding Seminar Nasional Teknik Kimia "Kejuangan" Pengembangan Teknologi Kimia untuk Pengolahan Sumber Daya Alam Indonesia.ISSN 1693-4393 hlmn I2-1 s/d I2-5.

UU No. 18 tahun 2008 tentang Pengelolaan Sampah.

UU No. 81 tahun 2012 tentang Pengelolaan Sampah Rumah Tangga dan Sampah Sejenis Sampah Rumah Tangga.

Zulkifli, A., 2014, Dasar-Dasar Ilmu Lingkungan, Salemba Teknika : Jakarta Selatan.

Widiarti, I.W., 2012, Pengelolaan Sampah Berbasis "Zero Waste" Skala Rumah Tangga Secara Mandiri, Jurnal Sains dan Teknologi Lingkungan ISSN: 2085-1227 Volume 4, Nomor 2, Juni 2012, Halaman 101-113.

Wintoko, B., 2011, Panduan Praktis Mendirikan Bank Sampah, Pustaka Baru : Jogja. 